\title{
State Estimation for Sound Environment System with Unknown Structure by Introducing Fuzzy Theory
}

\author{
Akira Ikuta Member (Prefectural University of Hiroshima, ikuta@pu-hiroshima.ac.jp) \\ Hisako Masuike Non-member (NTT DATA Chugoku,, masuikeh@nttdata-chugoku.co.jp) \\ Mitsuo Ohta Non-member (Hiroshima University, Emeritus)
}

Keywords : fuzzy adaptive filter, sound environment system, unknown structure, state estimation

The actual sound environment system exhibits various types of linear and non-linear characteristics, and it often contains an unknown structure. Furthermore, the observation data in the sound environment system contain the fuzziness due to several causes. For example, the human psychological evaluation for loudness of sound can be judged by use of 7 scores: 1.very calm, 2.calm, 3.mostly calm, 4.little noisy, 5.noisy, 6.fairly noisy, 7.very noisy. However, each score is affected by the human subjectivity and the borders between two neighboring scores are vague. In this situation, in order to evaluate the objective sound environment system, it is desirable to estimate the waveform fluctuation of the specific signal based on the observed data with fuzziness. In this study, based on the fuzzy observations, a method for estimating adaptively the specific signal for sound environment systems with unknown structural characteristic is theoretically proposed.

Let $x_{k}$ and $y_{k}$ be the input and output signals at a discrete time $k$ for a sound environment system. For example, for the psychological evaluation in sound environment, $x_{k}$ and $y_{k}$ denote respectively the physical sound level and human response quantity for it. Since the system characteristics are unknown, attention is focused on the conditional probability distribution function $P\left(x_{k} \mid y_{k}\right)$ reflecting all linear and nonlinear correlation between $x_{k}$ and $y_{k}$. Furthermore, let $z_{k}$ be the fuzzy observation obtained from $y_{k}$. For example, $z_{k}$ expresses one of 7 scores for the loudness of sound, taking the individual and psychological situation into consideration for $y_{k}$. The fuzziness of $z_{k}$ is characterized by the membership function $\mu_{z_{k}}\left(y_{k}\right)$ :

$$
\mu_{z_{k}}\left(y_{k}\right)=\exp \left\{-\alpha\left(y_{k}-z_{k}\right)^{2}\right\}
$$

where $\alpha(>0)$ is a parameter. Considering the correlation information between $x_{k}$ and $y_{k}$ as unknown parameter vector $\mathbf{a}_{k}$, a method to estimate $x_{k}$ based on the fuzzy observation $z_{k}$ is derived by applying two theories on probability measure of fuzzy events and moment statistics of fuzzy events to expansion series expressions of the conditional probability distribution function.

First, after focusing our attention on Bayes' theorem for the conditional probability distribution, by introducing probability measure of fuzzy events, the following expression can be derived.

$$
P\left(x_{k}, \mathbf{a}_{k} \mid Z_{k}\right)=\frac{\int \mu_{z_{k}}\left(y_{k}\right) P\left(x_{k}, \mathbf{a}_{k}, y_{k} \mid Z_{k-1}\right) d y_{k}}{\int \mu_{z_{k}}\left(y_{k}\right) P\left(y_{k} \mid Z_{k-1}\right) d y_{k}}
$$

where $Z_{k}\left(=\left\{z_{1}, z_{2}, \ldots, z_{k}\right\}\right)$ is a set of observation data up to time $k$. Based on Eq.(2), the recurrence algorithm for estimating an arbitrary polynomial type function of $x_{k}$ and $\mathbf{a}_{k}$ can be derived.

Though the parameter $\alpha$ in Eq.(1) can be generally given based on the prior information (or, through trial and error), it can be regarded as unknown parameter and estimated simultaneously with the specific signal $x_{k}$ and the parameter $\mathbf{a}_{k}$. After paying our attention to an expansion series expression on the conditional joint probability density function of $x_{k}, \mathbf{a}_{k}$ and $\alpha_{k}$, by applying moment statistics of fuzzy events to the expansion coefficients, the estimate of an arbitrary polynomial function of $x_{k}, \mathbf{a}_{k}$ and $\alpha_{k}$ can be derived.

The effectiveness of the proposed theory is confirmed by applying it to the estimation of sound level based on the successive observation of the evaluation scores for the loudness of sound. One of the estimated results of the sound level is shown in Fig.1. The proposed method considering fuzzy theory estimates precisely the waveform of the sound level with rapidly changing fluctuation.

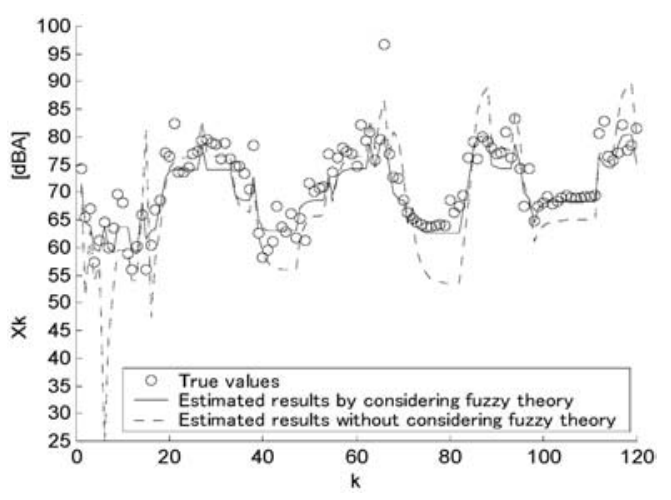

Fig. 1. Estimation results of the fluctuation waveform of the sound level based on the successive judgment on loudness scores 


\title{
ファジィ理論の導入による構造未知の音環境システム に対する状態推定
}

\author{
正 員 生田 顕* 非会員 益池 寿子** \\ 非会員 太田 光雄 $* * *$
}

\section{State Estimation for Sound Environment System with Unknown Structure by Introducing Fuzzy Theory}

Akira Ikuta*, Member, Hisako Masuike**, Non-member, Mitsuo Ohta***, Non-member

The actual sound environment system exhibits various types of linear and non-linear characteristics, and it often contains an unknown structure. Furthermore, the observations in the sound environment often contain fuzziness due to several causes. In this paper, a method for estimating the specific signal for sound environment system with unknown structure and fuzzy observation is proposed by introducing a fuzzy theory and a system model of the conditional probability type. The effectiveness of the proposed theoretical method is confirmed by applying it to the actual problem of the sound environment.

キーワード : ファジィ適応フィルタ，音環境システム，構造未知，状態推定

Keywords : fuzzy adaptive filter, sound environment system, unknown structure, state estimation

\section{1. はじめに}

現実の音環境システムは，さまざまな要因が複雑に絡み 合い，内部メカニズムを物理法則に基づきボトムアップの 立場から把握することが困難か，またはシステム特性が全 く未知な場合がしばしばである。しかも，観測される実際 の入出力時系列データ間には, 線形相関のみならず, 高次 の非線形相関情報までが確実に潜在している。

既発表では，従来の構造的解析法では系統的解析がかな り困難であった複雑・多様な実音環境システムに着目し, 入出力に関する低次はもちろん高次の各種相関情報をも展 開係数に反映させた級数展開表現による非線形のシステム モデルを提案した(1)。さらに，このシステムモデルを活用し た音環境計測における雑音対策法についても考察した ${ }^{(2)}$ 。提 案したシステムモデルにおいて，基本情報となるのは，入 出力変数に関する条件付確率密度関数であり，このうちに

\footnotetext{
* 県立広島大学

干734-8558 広島県広島市南区宇品東 1-1-71

Prefectural University of Hiroshima

1-1-71 Ujina-Higashi, Minami-ku, Hiroshima 734-8558

** NTT データ中国

干732-0816 広島県広島市南区比治山本町 11-20

NTT DATA Chugoku

11-20 Hijiyama, Minami-ku, Hiroshima 732-0816

*** 広島大学名誉教授

干732-0824 広島県広島市的場 1-7-10,1105

Hiroshima University, Emeritus

1105, 1-7-10 Matoba, Hiroshima 732-0824
}

入出力に関する線形・非線形のあらゆる相関情報が含まれ ている。

一方, 実音環境における観測データは非ガウス型の複雑 な変動分布を示し, しかも様々な要因により，しばしばあ いまいさが混入してくる。例えば，音の大きさ（ラウドネ ス）に対する人間の主観性や計測における不確実性・信頼 性の存在, さらに観測データのディジタル化に伴う量子化 誤差など, 様々なあいまいさが存在する。したがって, 対 象とする音環境を合理的に評価するためには, あいまいさ を含むファジィ観測データから, 刻々と変化する対象信号 の変動波形を精密に推定することが基本となる。

以上の観点から, 本研究では, あいまいさが混入したフ アジィ観測データに基づき，対象信号を推定するためのフ アジィ適応フィルタについて考察を行っている。具体的に は，システム特性を一般に未知として捉えざるを得ない人 間の応答系を含めた複雑な音環境システムに着目し, 音の 大きさに対する 7 段階での人間の心理評価 (1.「非常に静か」

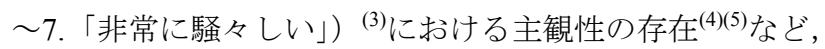
あいまいさを含む観測值に配慮して, ファジィ観測データ から対象信号の原変動波形を推定するための一手法を提案 する。その際, 対象信号と観測值との関連情報としては, 既発表の条件付確率密度に関する級数展開表現 ${ }^{(1)}$ を採用し, その展開係数を未知パラメータとみなすことにより対象信 号と同時に推定する。 
最後に，本質的にあいまいさの伴う音の大きさに対する 心理評価值からでも，これに整合した関係本態論の定量的 手法が何れかあれば，一逆問題として，もとの信号の瞬時 レベル変動を刻々とかなり合理的に推定し得ることを，理 論の設定とともにその有効性を実験的にも検証している。

\section{2. 未知構造とファジィ観測の音環境システムに 対する定式化}

内部メカニズムに基づき，構造的立場からシステム特性 を捉えることが困難か全く不可能な, 複雑な音環境システ ムに着目する。現実の音環境における観測においては，た とえば音の大きさ（ラウドネス）に対する人間の主観性や 計測における不確実性・信頼性の存在など，さまざまなあ いまいさが存在する。このような構造未知の音環境システ

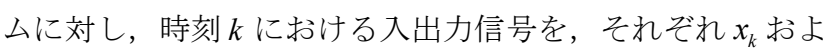
び $y_{k}$ とする。たとえば音環境の心理評価において， $x_{k}$ は物 理的な騒音レベルを， $y_{k}$ はそれに対する人間の反応を表す。 $x_{k}$ と $y_{k}$ との関係は複雑で, 一般には未知として取り扱うこ とが必要となる。本研究では, 両者の関係を条件付確率分 布 $P\left(y_{k} \mid x_{k}\right)$ で捉えることにする。さらに， $y_{k}$ の観測の際に 混入する，あいまいさを含んだファジィ観測值を $z_{k}$ とする。 たとえば $z_{k}$ は， $y_{k}$ に対し音の大きさを音響心理学の分野で 通常行われるように，7段階 (1. 非常に静か, 2. 静か, 3. 大 体静か, 4. 少し騒々しい, 5. 騒々しい, 6. かなり騒々しい, 7. 非常に騒々しい) で評価したときのラウドネス評価值を 表す(3)。これらの隣接した 2 評価值間の境界はあいまいであ り，しかも人間の主観に依存しており個人差も存在するこ とから，あいまいさを含むファジィ観測值 $z_{k}$ として捉える。 本研究では, このあいまいさに対し次のメンバーシップ関 数を導入する。

$$
\mu_{z_{k}}\left(y_{k}\right)=\exp \left\{-\alpha\left(y_{k}-z_{k}\right)^{2}\right\}
$$

ただし $\alpha(>0)$ はメンバーシップ関数の形状に関するパラメ ータである。

$x_{k}$ 及び $y_{k}$ に関する結合確率分布 $P\left(x_{k}, y_{k}\right)$ を, 既発表と同 様に ${ }^{(2)}$, それぞれの変数に関する周辺分布 $P\left(x_{k}\right)$ と $P\left(y_{k}\right)$ の 積を基幹として直交級数展開することにより, 次の条件付 確率分布に対する級数展開表示が得られる。

$$
\begin{aligned}
& P\left(y_{k} \mid x_{k}\right)=P\left(y_{k}\right) \sum_{r=0}^{R} \sum_{s=0}^{S} A_{r s} \theta_{r}^{(1)}\left(x_{k}\right) \theta_{s}^{(2)}\left(y_{k}\right) \\
& A_{r s} \equiv<\theta_{r}^{(1)}\left(x_{k}\right) \theta_{s}^{(2)}\left(y_{k}\right)>
\end{aligned}
$$

ただし， < >は平均操作を意味する。 $x_{k}$ と $y_{k}$ 間の線形・ 非線形の各種相関情報は, 各展開係数 $A_{r s}$ の内に階層的に反 映されている。関数 $\theta_{r}^{(1)}\left(x_{k}\right)$ と $\theta_{s}^{(2)}\left(y_{k}\right)$ は，それぞれ $P\left(x_{k}\right)$ と $P\left(y_{k}\right)$ を重みとする正規直交関数で, シュミットの直交化法 を用いて構成される ${ }^{(6)}$ 。(2)式はもともと無限級数表現であ るが, 現実には有限項数のみ利用可能であり, 実用的には 最初の数項のみの考慮で対応できることから有限展開表現 $(r \leq R, s \leq S)$ を採用した。
本研究では, 因果関係とは反対の逆問題として, ファジ イ観測データ $z_{k}$ に基づき未知の対象信号 $x_{k}$ を推定するため のファジィ適応フィルタを提案する。ここで, 対象とする 音環境システムは未知対象信号および未知システム構造を 含むことから， (3)式で定義される展開係数 $A_{r s}$ はファジィ 観測データ $z_{k}$ に基づき推定することが必要である。したが って, 展開係数 $A_{r s}$ を次式のごとく未知パラメータ $\mathbf{a}$ とみな ᄂ,

$$
\begin{aligned}
& \mathbf{a} \equiv\left(a_{1}, a_{2}, \ldots, a_{I}\right) \equiv\left(\mathbf{a}_{(1)}, \mathbf{a}_{(2)}, \ldots, \mathbf{a}_{(S)}\right) \\
& \mathbf{a}_{(s)} \equiv\left(A_{1 s}, A_{2 s}, \ldots, A_{R s}\right),(s=1,2, \ldots, S)
\end{aligned}
$$

対象信号 $x_{k}$ と同時推定するために, 次の時不変なパラメー タに関するシステム方程式を導入する。

$$
\left.\mathbf{a}_{k+1}=\mathbf{a}_{k} \ldots\left(a_{1, k}, a_{2, k}, \ldots, a_{I, k}\right) \equiv\left(\mathbf{a}_{(1), k}, \mathbf{a}_{(2), k}, \ldots, \mathbf{a}_{(S), k}\right)\right)
$$

ただし， $I(=R \cdot S)$ は推定すべき展開係数の個数である。

一方, 非ガウス型の変動を示す対象信号に対し, 対象の 時間的相関情報を基に, 時間推移則が次のように設定され $3^{(6)}$ 。

$x_{k+1}=F x_{k}+G u_{k}$

ただし $u_{k}$ は平均 0 で分散 $\sigma_{u}^{2}$ の白色雑音である。

\section{3. ファジィ適応フィルタによる状態推定}

〈3・1〉 ファジィ確率に基づく推定法の導出 ファジ イ観測データ $z_{k}$ の逐次摂取に基づき, 対象信号 $x_{k}$ を推定す るためのファジィ適応フィルタを導出するにあたり, 既発 表 ${ }^{(2)(6)}$ と同様に, 推定の基本原理である, 逆確率としてのべ イズ定理に着目する。ただし，パラメータ $\mathbf{a}_{k}$ も知である ため, $x_{k}$ と $\mathbf{a}_{k}$ に関する条件付結合確率分布に着目する。

$$
P\left(x_{k}, \mathbf{a}_{k} \mid Z_{k}\right)=\frac{P\left(x_{k}, \mathbf{a}_{k}, z_{k} \mid Z_{k-1}\right)}{P\left(z_{k} \mid Z_{k-1}\right)}
$$

ここで, $Z_{k}\left(=\left\{z_{1}, z_{2}, \ldots, z_{k}\right\}\right)$ は時刻 $k$ までの観測值の集合であ る。( 7 )式の右辺にファジィ事象の確率(7)を適用した後, 直 交展開することにより, 条件付確率密度関数 $P\left(x_{k}, \mathbf{a}_{k} \mid Z_{k}\right)$ は 次のように変形される (ファジィ事象を含むべイズ確率)。

$$
\begin{aligned}
P\left(x_{k}, \mathbf{a}_{k} \mid Z_{k}\right)= & \frac{\int \mu_{z_{k}}\left(y_{k}\right) P\left(x_{k}, \mathbf{a}_{k}, y_{k} \mid Z_{k-1}\right) d y_{k}}{\int \mu_{z_{k}}\left(y_{k}\right) P\left(y_{k} \mid Z_{k-1}\right) d y_{k}} \\
= & \sum_{l=0}^{\infty} \sum_{\mathbf{m}=\mathbf{0}}^{\infty} \sum_{n=0}^{\infty} B_{l \mathbf{m} n} P_{0}\left(x_{k} \mid Z_{k-1}\right) P_{0}\left(\mathbf{a}_{k} \mid Z_{k-1}\right) \\
& \varphi_{l}^{(1)}\left(x_{k}\right) \varphi_{\mathbf{m}}^{(2)}\left(\mathbf{a}_{k}\right) I_{n}\left(z_{k}\right) / \sum_{n=0}^{\infty} B_{00 n} I_{n}\left(z_{k}\right)
\end{aligned}
$$

ただし

$$
\begin{aligned}
I_{n}\left(z_{k}\right) \equiv & \int \mu_{z_{k}}\left(y_{k}\right) P_{0}\left(y_{k} \mid Z_{k-1}\right) \varphi_{n}^{(3)}\left(y_{k}\right) d y_{k} \\
B_{l \mathbf{m} n} \equiv & <\varphi_{l}^{(1)}\left(x_{k}\right) \varphi_{\mathbf{m}}^{(2)}\left(\mathbf{a}_{k}\right) \varphi_{n}^{(3)}\left(y_{k}\right) \mid Z_{k-1}>\cdots \\
& \left(\mathbf{m} \equiv\left(m_{1}, m_{2}, \ldots, m_{I}\right)\right)
\end{aligned}
$$

である。関数 $\varphi_{l}^{(1)}\left(x_{k}\right), \varphi_{\mathbf{m}}^{(2)}\left(\mathbf{a}_{k}\right), \varphi_{n}^{(3)}\left(y_{k}\right)$ は, それぞれの变数 に対する基準分布 $P_{0}\left(x_{k} \mid Z_{k-1}\right), \quad P_{0}\left(\mathbf{a}_{k} \mid Z_{k-1}\right), \quad P_{0}\left(y_{k} \mid Z_{k-1}\right)$ を 重みとする正規直交多項式である。 
( 8 )式を基に, $x_{k}$ および $\mathbf{a}_{k}$ に関する任意 $(L, \mathbf{M})$ 次多項式 関数 $f_{L, \mathbf{M}}\left(x_{k}, \mathbf{a}_{k}\right)$ に対する推定式が次のごとく得られる。

$$
\begin{aligned}
\hat{f}_{L, \mathbf{M}}\left(x_{k}, \mathbf{a}_{k}\right) \equiv & <f_{L, \mathbf{M}}\left(x_{k}, \mathbf{a}_{k}\right) \mid Z_{k}> \\
= & \frac{\sum_{l=0}^{L} \sum_{\mathbf{m}=\mathbf{0}}^{\mathbf{M}} \sum_{n=0}^{\infty} C_{l \mathbf{m}}^{L \mathbf{M}} B_{l \mathbf{m} n} I_{n}\left(z_{k}\right)}{\sum_{n=0}^{\infty} B_{00} I_{n}\left(z_{k}\right)}
\end{aligned}
$$

ここで $C_{l \mathrm{~m}}^{L \mathrm{M}}$ は次式を満足する係数である。

$$
f_{L, \mathbf{M}}\left(x_{k}, \mathbf{a}_{k}\right)=\sum_{l=0}^{L} \sum_{\mathbf{m}=\mathbf{0}}^{\mathbf{M}} C_{l \mathbf{m}}^{L \mathbf{M}} \varphi_{l}^{(1)}\left(x_{k}\right) \varphi_{\mathbf{m}}^{(2)}\left(\mathbf{a}_{k}\right)
$$

以上の一般理論を具体化するため, 規準分布 $P_{0}\left(x_{k} \mid Z_{k-1}\right)$, $P_{0}\left(\mathbf{a}_{k} \mid Z_{k-1}\right), P_{0}\left(y_{k} \mid Z_{k-1}\right)$ として, 公知の標準的なガウス分 布を採用する。

$$
\begin{aligned}
& P_{0}\left(x_{k} \mid Z_{k-1}\right)=N\left(x_{k} ; x_{k}^{*}, \Gamma_{x_{k}}\right) \\
& P_{0}\left(\mathbf{a}_{k} \mid Z_{k-1}\right)=\prod_{i=1}^{I} N\left(a_{i, k} ; a_{i, k}^{*}, \Gamma_{a_{i, k}}\right) \\
& P_{0}\left(y_{k} \mid Z_{k-1}\right)=N\left(y_{k} ; y_{k}^{*}, \Omega_{k}\right)
\end{aligned}
$$

ただし

$$
\begin{aligned}
& N\left(x ; \mu, \sigma^{2}\right) \equiv \frac{1}{\sqrt{2 \pi \sigma^{2}}} \exp \left\{-\frac{(x-\mu)^{2}}{2 \sigma^{2}}\right\} \\
& x_{k}^{*} \equiv<x_{k}\left|Z_{k-1}>, \Gamma_{x_{k}} \equiv<\left(x_{k}-x_{k}^{*}\right)^{2}\right| Z_{k-1}> \\
& a_{i, k}^{*} \equiv<a_{i, k}^{*}\left|Z_{k-1}>, \Gamma_{a_{i, k}} \equiv<\left(a_{i, k}-a_{i, k}^{*}\right)^{2}\right| Z_{k-1}> \\
& y_{k}^{*} \equiv<y_{k}\left|Z_{k-1}>, \Omega_{k}=<\left(y_{k}-y_{k}^{*}\right)^{2}\right| Z_{k-1}>
\end{aligned}
$$

で定義される。したがって，(13)式を重みとする各直交多項 式はエルミート多項式で与えられる ${ }^{(8)}$ :

$$
\begin{aligned}
& \varphi_{l}^{(1)}\left(x_{k}\right)=\frac{1}{\sqrt{l !}} H_{l}\left(\frac{x_{k}-x_{k}^{*}}{\sqrt{\Gamma_{x_{k}}}}\right) \\
& \varphi_{\mathbf{m}}^{(2)}\left(\mathbf{a}_{k}\right)=\prod_{i=1}^{I} \frac{1}{\sqrt{m_{i} !}} H_{m_{i}}\left(\frac{a_{i, k}-a_{i, k}^{*}}{\Gamma_{a_{i, k}}}\right) \\
& \varphi_{n}^{(3)}\left(y_{k}\right)=\frac{1}{\sqrt{n !}} H_{n}\left(\frac{y_{k}-y_{k}^{*}}{\Omega_{k}}\right)
\end{aligned}
$$

(1)(13)(15)式を考慮することにより，(9)式は次のように具 体化される。

$$
\begin{aligned}
& I_{n}\left(z_{k}\right)=\frac{e^{K_{3}\left(z_{k}\right)}}{\sqrt{2 K_{1} \Omega_{k}}} \int \frac{1}{\sqrt{\pi / K_{1}}} \exp \left\{-\frac{\left(y_{k}-K_{2}\left(z_{k}\right)\right)^{2}}{1 / K_{1}}\right\} \\
& \cdot \frac{1}{\sqrt{n !}} \sum_{r=0}^{n} d_{n r} H_{r}\left(\frac{y_{k}-K_{2}\left(z_{k}\right)}{\sqrt{1 / 2 K_{1}}}\right) d y_{k}
\end{aligned}
$$

ただし

$$
\begin{aligned}
& K_{1} \equiv \frac{2 \alpha \Omega_{k}+1}{2 \Omega_{k}}, \quad K_{2}\left(z_{k}\right) \equiv \frac{2 \alpha \Omega_{k} z_{k}+y_{k}^{*}}{2 \alpha \Omega_{k}+1} \\
& K_{3}\left(z_{k}\right) \equiv K_{1}\left(K_{2}^{2}\left(z_{k}\right)-\frac{2 \alpha \Omega_{k} z_{k}^{2}+y_{k}^{* 2}}{2 \alpha \Omega_{k}+1}\right) \cdots . .
\end{aligned}
$$

である。ここで, ファジィ観測值 $z_{k}$ は, 関数 $K_{2}\left(z_{k}\right)$ および $K_{3}\left(z_{k}\right)$ に反映されている。また, $d_{n r}(r=0,1,2, \ldots, n)$ は
次式を満足する展開係数である。

$$
H_{n}\left(\frac{y_{k}-y_{k}^{*}}{\sqrt{\Omega_{k}}}\right)=\sum_{r=0}^{n} d_{n r} H_{r}\left(\frac{y_{k}-K_{2}\left(z_{k}\right)}{\sqrt{1 / 2 K_{1}}}\right)
$$

エルミート多項式の直交条件 ${ }^{(8)}$ を考慮することにより， 式は次のように表現される。

$$
I_{n}\left(z_{k}\right)=\frac{e^{K_{3}\left(z_{k}\right)}}{\sqrt{2 K_{1} \Omega_{k} n !}} d_{n 0}
$$

ただし，上式における $d_{n 0}$ は具体的には次式で与えられる。

$$
\begin{aligned}
d_{00} \equiv 1, \quad d_{10} \equiv \frac{1}{\sqrt{\Omega_{k}}}\left(K_{2}\left(z_{k}\right)-y_{k}^{*}\right) \\
d_{20} \equiv \frac{\left(K_{2}\left(z_{k}\right)-y_{k}^{*}\right)^{2}}{\Omega_{k}}+\frac{1}{2 K_{1} \Omega_{k}}-1 \\
d_{30} \equiv \frac{3\left(K_{2}\left(z_{k}\right)-y_{k}^{*}\right)}{2 K_{1} \Omega_{k}^{3 / 2}}-\frac{3\left(K_{2}\left(z_{k}\right)-y_{k}^{*}\right)}{\sqrt{\Omega_{k}}}+\frac{\left(K_{3}\left(z_{k}\right)-y_{k}^{*}\right)^{3}}{\Omega_{k}^{3 / 2}} \\
d_{40} \equiv \frac{3}{\left(2 \Omega_{k} K_{1}\right)^{2}}+\frac{3\left\{\left(K_{2}\left(z_{k}\right)-y_{k}^{*}\right)^{2}-\Omega_{k}\right\}}{\Omega_{k}^{2} K_{1}} \\
+\frac{\left(K_{2}\left(z_{k}\right)-y_{k}^{*}\right)^{4}-6 \Omega_{k}\left(K_{2}\left(z_{k}\right)-y_{k}^{*}\right)^{2}+3 \Omega_{k}^{2}}{\Omega_{k}^{2}}
\end{aligned}
$$

従つて, (12)式で特に $f_{1, \mathbf{0}}\left(x_{k}, \mathbf{a}_{k}\right)=x_{k}, f_{2, \mathbf{0}}\left(x_{k}, \mathbf{a}_{k}\right)=\left(x_{k}-\hat{x}_{k}\right)^{2}$ および $f_{0,0 \ldots 010 \ldots 0}\left(x_{k}, \mathbf{a}_{k}\right)=a_{i, k}, \quad f_{0,0 \ldots 020 \ldots 0}\left(x_{k}, \mathbf{a}_{k}\right)=\left(a_{i, k}-\hat{a}_{i, k}\right)^{2}$ と おくことにより, $x_{k}$ および $a_{i, k}$ の平均, 分散に対する推定式 は，それぞれ次のように具体的に表される。

$$
\hat{x}_{k} \equiv<x_{k} \mid Z_{k}>
$$

$$
\begin{aligned}
&=\frac{\sum_{n=0}^{\infty}\left\{C_{00}^{10} B_{00 n}+C_{10}^{10} B_{10 n}\right\} I_{n}\left(z_{k}\right)}{\sum_{n=0}^{\infty} B_{00 n} I_{n}\left(z_{k}\right)} \ldots \ldots \ldots \ldots \ldots \ldots \ldots . . . . \\
& \hat{P}_{k} \equiv<\left(x_{k}-\hat{x}_{k}\right)^{2} \mid Z_{k}> \\
&=\frac{\sum_{n=0}^{\infty}\left\{C_{00}^{20} B_{00 n}+C_{10}^{20} B_{10 n}+C_{20}^{20} B_{20 n}\right\} I_{n}\left(z_{k}\right)}{\sum_{n=0}^{\infty} B_{00 n} I_{n}\left(z_{k}\right)}
\end{aligned}
$$

$$
\begin{aligned}
\hat{a}_{i, k} \equiv & <a_{i, k} \mid Z_{k}> \\
& =\frac{\sum_{n=0}^{\infty}\left\{C_{0 \cdots 0 \cdots 0}^{0 \cdots \cdots 0} B_{0 \cdots 0 \cdots n}+C_{0 \cdots 1 \cdots 0}^{0 \cdots \cdots 0} B_{0 \cdots 1 \cdots n}\right\} I_{n}\left(z_{k}\right)}{\sum_{n=0}^{\infty} B_{00 n} I_{n}\left(z_{k}\right)}
\end{aligned}
$$

$$
\begin{aligned}
\hat{P}_{a_{i, k}} \equiv & <\left(a_{i, k}-\hat{a}_{i, k}\right)^{2} \mid Z_{k}> \\
= & \frac{\sum_{n=0}^{\infty}\left\{C_{0 \cdots 0 \cdots 0}^{0 \cdots 2 \cdots 0} B_{00 n}+C_{0 \cdots 1 \cdots 0}^{0 \cdots \cdots 0} B_{0 \cdots 1 \cdots n}+C_{0 \cdots 2 \cdots 0}^{0 \cdots 2 \cdots 0} B_{0 \cdots 2 \cdots n}\right\} I_{n}\left(z_{k}\right)}{\sum_{n=0}^{\infty} B_{00 n} I_{n}\left(z_{k}\right)}
\end{aligned}
$$


ただし

$$
\begin{aligned}
& C_{00}^{10} \equiv x_{k}^{*}, \quad C_{10}^{10} \equiv \sqrt{\Gamma_{x_{k}}}, \quad C_{00}^{20} \equiv \Gamma_{x_{k}}+\left(x_{k}^{*}-\hat{x}_{k}\right)^{2} \\
& C_{10}^{20} \equiv 2 \sqrt{\Gamma_{x_{k}}}\left(x_{k}^{*}-\hat{x}_{k}\right), \quad C_{20}^{20} \equiv \sqrt{2} \Gamma_{x_{k}} \\
& C_{0 \cdots \cdots 0}^{0 \cdots 1 \cdots 0} \equiv a_{i, k}^{*}, \quad C_{0 \cdots 1 \cdots 0}^{0 \cdots \cdots 0} \equiv \sqrt{\Gamma_{a_{i, k}}^{0 \cdots \cdots}} \\
& C_{0 \cdots 0}^{0 \cdots 2 \cdots 0} \equiv \Gamma_{a_{i, k}}+\left(a_{i, k}^{*}-\hat{a}_{i, k}\right)^{2} \\
& C_{0 \cdots 1 \cdots 0}^{0 \cdots \cdots 0} \equiv 2 \sqrt{\Gamma_{a_{i, k}}}\left(a_{i, k}^{*}-\hat{a}_{i, k}\right), \quad C_{0 \cdots 2 \cdots 0}^{0 \cdots 2 \cdots 0} \equiv \sqrt{2} \Gamma_{a_{i, k}}
\end{aligned}
$$

である。さらに，条件付期待值の性質と(2)式を用いること により，(13)式における 2 つのパラメータ $y_{k}^{*} と \Omega_{k}$ は, 次の ように時刻 $k-1$ における $x_{k}$ と $\mathbf{a}_{k}$ の予測值 $\left(Z_{k-1}\right.$ で条件付け られた $x_{k}$ と $\mathbf{a}_{k}$ の任意関数に関する期待值）で表される。

$$
\begin{aligned}
y_{k}^{*} & =<y_{k}\left|x_{k}, Z_{k-1}>\right| Z_{k-1}> \\
& =<\int y_{k} P\left(y_{k} \mid x_{k}\right) d y_{k} \mid Z_{k-1}> \\
& =\sum_{s=0}^{1} e_{1 s}<\mathbf{A}_{(s), k} \Theta\left(x_{k}\right) \mid Z_{k-1}>\cdots \ldots \ldots . . . \\
\Omega_{k} & =<\int\left(y_{k}-y_{k}^{*}\right)^{2} P\left(y_{k} \mid x_{k}\right) d y_{k} \mid Z_{k-1}> \\
& =\sum_{s=0}^{2} e_{2 s}<\mathbf{A}_{(s), k} \Theta\left(x_{k}\right) \mid Z_{k-1}>\cdots \cdots \cdots
\end{aligned}
$$

ただし

$$
\begin{aligned}
& \mathbf{A}_{(s), k} \equiv\left(0, \mathbf{a}_{(s), k}\right),(s=1,2, \cdots) \\
& \mathbf{A}_{(0), k} \equiv(1,0,0, \cdots, 0) \\
& \Theta\left(x_{k}\right) \equiv\left(\theta_{0}^{(1)}\left(x_{k}\right), \theta_{1}^{(1)}\left(x_{k}\right), \cdots, \theta_{R}^{(1)}\left(x_{k}\right)\right)^{T}
\end{aligned}
$$

である。また，(26)(27)式における $e_{1 s}, e_{2 s}$ は， $y_{k}$ および $\left(y_{k}-y_{k}^{*}\right)^{2}$ に対する次の直交展開式を満足するように予め決 定される係数である。

$$
y_{k}=\sum_{i=0}^{1} e_{1 i} \theta_{i}^{(2)}\left(y_{k}\right), \quad\left(y_{k}-y_{k}^{*}\right)^{2}=\sum_{i=0}^{2} e_{2 i} \theta_{i}^{(2)}\left(y_{k}\right)
$$

同様に，(10)式で定義される展開係数 $B_{l \mathrm{~m} n}$ は，(2)式および 関数 $\theta_{i}^{(2)}\left(y_{k}\right)$ の直交条件を考慮することにより, 次のように 与えられる。

$$
\begin{aligned}
B_{l \mathbf{m} n} & =<\varphi_{l}^{(1)}\left(x_{k}\right) \varphi_{\mathbf{m}}^{(2)}\left(\mathbf{a}_{k}\right) \int \varphi_{n}^{(3)}\left(y_{k}\right) P\left(y_{k} \mid x_{k}\right) d y_{k} \mid Z_{k-1}> \\
& =\sum_{s=0}^{n} e_{n s}<\varphi_{l}^{(1)}\left(x_{k}\right) \varphi_{\mathbf{m}}^{(2)}\left(\mathbf{a}_{k}\right) \mathbf{A}_{(s), k} \Theta\left(x_{k}\right) \mid Z_{k-1}>
\end{aligned}
$$

$$
\left(\varphi_{n}^{(3)}\left(y_{k}\right)=\sum_{i=0}^{n} e_{n i} \theta_{i}^{(2)}\left(y_{k}\right), e_{n i} ; \text { 一意に決定される係数 }\right)
$$

(30)式から，展開係数 $B_{l \mathrm{~m} n}$ は $x_{k}$ および $\mathbf{a}_{k}$ の予測值で与えら れることがわかる。なお， $y_{k}$ に対する推定值も，(2)式を 考慮することにより， $x_{k}$ の多項式に関する推定值から算定 できる(付録参照)。

最後に(5)(6)式を考慮することにより，逐次推定を行う
上で必要な予測值は，平均，分散に関して次式で与えられ る。

$$
\begin{aligned}
& x_{k+1}^{*} \equiv<x_{k+1} \mid Z_{k}>=F \hat{x}_{k} \\
& \Gamma_{k+1} \equiv<\left(x_{k+1}-x_{k+1}^{*}\right)^{2} \mid Z_{k}>=F^{2} \hat{P}_{k}+G^{2} \sigma_{u}^{2} \\
& a_{i, k+1}^{*} \equiv<a_{i, k+1}\left|Z_{k}>=<a_{i, k}\right| Z_{k}>=\hat{a}_{i, k} \\
& \Gamma_{a_{i, k+1}} \equiv<\left(a_{i, k+1}-a_{i, k+1}^{*}\right)^{2} \mid Z_{k}> \\
& =<\left(a_{i, k}-\hat{a}_{i, k}\right)^{2} \mid Z_{k}>=\hat{P}_{a_{i, k}}
\end{aligned}
$$

〈3·2〉 ファジィ事象のモーメントに基づく推定法の導

出 (1)式におけるパラメータ $\alpha$ は、一般に先験情報をも とに（または試行錯誤で）決定することができるが，ここ ではこれも未知パラメータとみなすことにより, 対象騒音 $x_{k}$ および( 5$)$ 式で定義されるとパラメータ $\mathbf{a}_{k}$ と同時に推定 する。そのため, まず時不変パラメータ $\alpha$ に関する次の時 間推移則を導入する。

$$
\alpha_{k+1}=\alpha_{k}
$$

次に, (7)式と同様に, $x_{k}, \mathbf{a}_{k}$ および $\alpha_{k}$ に関する条件付結 合確率密度関数に着目すると, 次のベイズ定理に関する展 開表現が得られる。

$$
\begin{gathered}
P\left(x_{k}, \mathbf{a}_{k}, \alpha_{k} \mid Z_{k}\right)=\frac{P\left(x_{k}, \mathbf{a}_{k}, \alpha_{k}, z_{k} \mid Z_{k-1}\right)}{P\left(z_{k} \mid Z_{k-1}\right)} \\
=P_{0}\left(x_{k} \mid Z_{k-1}\right) P_{0}\left(\mathbf{a}_{k} \mid Z_{k-1}\right) P_{0}\left(\alpha_{k} \mid Z_{k-1}\right) \\
\sum_{l=0}^{\infty} \sum_{\mathbf{m}=\mathbf{0}}^{\infty} \sum_{n=0}^{\infty} \sum_{r=0}^{\infty} D_{l \mathbf{m} n r} \varphi_{l}^{(1)}\left(x_{k}\right) \varphi_{\mathbf{m}}^{(2)}\left(\mathbf{a}_{k}\right) \\
\varphi_{n}^{(4)}\left(\alpha_{k}\right) \varphi_{r}^{(5)}\left(z_{k}\right) / \sum_{r=0}^{\infty} D_{000 r} \varphi_{r}^{(5)}\left(z_{k}\right) \cdots \cdots
\end{gathered}
$$

ただし

$$
D_{l \mathbf{m} n r} \equiv<\varphi_{l}^{(1)}\left(x_{k}\right) \varphi_{\mathbf{m}}^{(2)}\left(\mathbf{a}_{k}\right) \varphi_{n}^{(4)}\left(\alpha_{k}\right) \varphi_{r}^{(5)}\left(z_{k}\right) \mid Z_{k-1}>
$$

であり, 関数 $\varphi_{n}^{(4)}\left(\alpha_{k}\right)$ および $\varphi_{r}^{(5)}\left(z_{k}\right)$ は, それぞれ $\alpha_{k}$ および $z_{k}$ に関する規準分布 $P_{0}\left(\alpha_{k} \mid Z_{k-1}\right)$ および $P_{0}\left(z_{k} \mid Z_{k-1}\right)$ を重み とする直交多項式である。

(36)式をもとに，(11)式と同様に $x_{k}, \mathbf{a}_{k}$ および $\alpha_{k}$ に関す る任意 $(L, \mathbf{M}, N)$ 次の多項式関数 $f_{L, \mathbf{M}, N}\left(x_{k}, \mathbf{a}_{k}, \alpha_{k}\right)$ に対する推 定式が次のように得られる。

$$
\begin{aligned}
& \hat{f}_{L, \mathbf{M}, N}\left(x_{k}, \mathbf{a}_{k}, \alpha_{k}\right) \equiv<f_{L, \mathbf{M}, N}\left(x_{k}, \mathbf{a}_{k}, \alpha_{k}\right) \mid Z_{k-1}> \\
& =\frac{\sum_{l=0}^{L} \sum_{\mathbf{m}=\mathbf{0}}^{\mathbf{M}} \sum_{n=0}^{N} \sum_{r=0}^{\infty} E_{l \mathbf{m} n}^{L \mathbf{M N}} D_{l \mathbf{m} n r} \varphi_{r}^{(5)}\left(z_{k}\right)}{\sum_{r=0}^{\infty} D_{000 r} \varphi_{r}^{(5)}\left(z_{k}\right)}
\end{aligned}
$$

ただし, $E_{l \mathbf{m} n}^{L \mathbf{M} N}$ は関数 $f_{L, \mathbf{M}, N}\left(x_{k}, \mathbf{a}_{k}, \alpha_{k}\right)$ を次のように直交展開 したときの係数である。

$$
\begin{aligned}
f_{L, \mathbf{M}, N} & \left(x_{k}, \mathbf{a}_{k}, \alpha_{k}\right) \\
& =\sum_{l=0}^{L} \sum_{\mathbf{m}=\mathbf{0}}^{\mathbf{M}} \sum_{n=0}^{N} E_{l \mathbf{m} n}^{L \mathbf{M} N} \varphi_{l}^{(1)}\left(x_{k}\right) \varphi_{\mathbf{m}}^{(2)}\left(\mathbf{a}_{k}\right) \varphi_{n}^{(4)}\left(\alpha_{k}\right)
\end{aligned}
$$

(37)式で定義される展開係数に, ファジィ事象の平均およ び分散 ${ }^{(7)}$ を任意次数の積率 (モーメント) に拡張し適用した 後, (2)式および関数 $\theta_{i}^{(2)}\left(y_{k}\right)$ の直交条件を適用することに より, 次式が得られる。 


$$
\begin{aligned}
D_{l \mathbf{m} n r}= & <\varphi_{l}^{(1)}\left(x_{k}\right) \varphi_{\mathbf{m}}^{(2)}\left(\mathbf{a}_{k}\right) \varphi_{n}^{(4)}\left(\alpha_{k}\right) \mu_{z_{k}}\left(y_{k}\right) \\
& \varphi_{r}^{(5)}\left(y_{k}\right)\left|Z_{k-1}>/<\mu_{z_{k}}\left(y_{k}\right)\right| Z_{k-1}> \\
= & \sum_{s=0}^{S} g_{s}<\varphi_{l}^{(1)}\left(x_{k}\right) \varphi_{\mathbf{m}}^{(2)}\left(\mathbf{a}_{k}\right) \varphi_{n}^{(4)}\left(\alpha_{k}\right) \mathbf{A}_{(s), k} \\
& \Theta\left(x_{k}\right)\left|Z_{k-1}>/ \sum_{s=0}^{S} h_{s}<\mathbf{A}_{(s), k} \Theta\left(x_{k}\right)\right| Z_{k-1}>
\end{aligned}
$$

ただし， $g_{s}$ および $h_{s}$ は，次式を満足する展開係数である。

$$
\begin{aligned}
& \mu_{z_{k}}\left(y_{k}\right) \varphi_{r}^{(5)}\left(y_{k}\right)=\sum_{i=0}^{\infty} g_{i} \theta_{i}^{(2)}\left(y_{k}\right) \\
& \mu_{z_{k}}\left(y_{k}\right)=\sum_{i=0}^{\infty} h_{i} \theta_{i}^{(2)}\left(y_{k}\right)
\end{aligned}
$$

さらに, (5)(6)(35)式を考慮することにより, 任意 $(L, \mathbf{M}, N)$ 次の多項式関数 $g_{L, \mathbf{M}, N}\left(x_{k+1}, \mathbf{a}_{k+1}, \alpha_{k+1}\right)$ に対する予測值は次式 で与えられる。

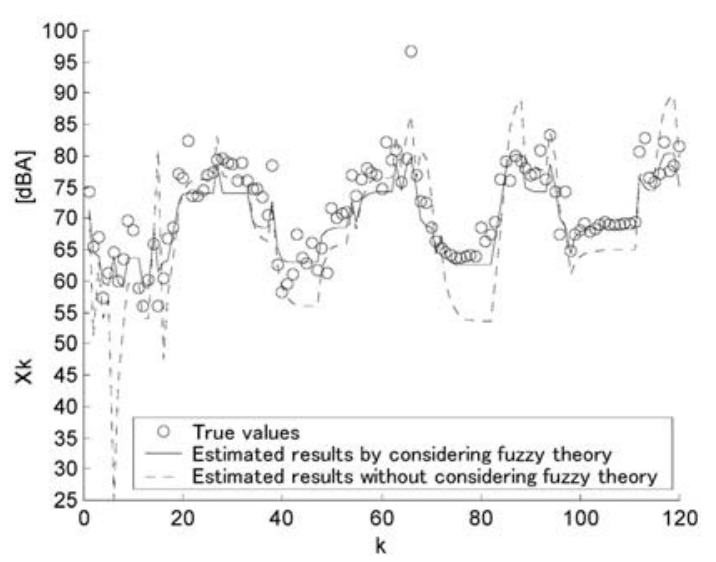

図 1 被験者 $\mathrm{A}$ によるラウドネスの逐次評価に基づく騒音 レベル変動波形の推定結果（データ 1 の場合）

Fig. 1. Estimation results of the fluctuation waveform of the sound level based on the successive judgment on loudness scores by a subject A (for Data 1).

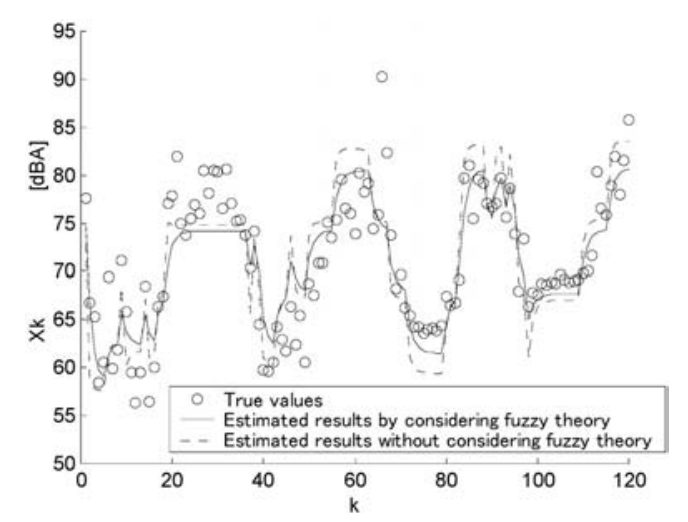

図 2 被験者 $\mathrm{B}$ によるラウドネスの逐次評価に基づく騒音 レベル変動波形の推定結果（データ 1 の場合）

Fig. 2. Estimation results of the fluctuation waveform of the sound level based on the successive judgment on loudness scores by a subject B (for Data 1).

$$
\begin{aligned}
& g_{L, \mathbf{M}, N}^{*}\left(x_{k+1}, \mathbf{a}_{k+1}, \alpha_{k+1}\right) \equiv<g_{L, \mathbf{M}, N}\left(x_{k+1}, \mathbf{a}_{k+1}, \alpha_{k+1}\right) \mid Z_{k}> \\
& =<g_{L, \mathbf{M}, N}\left(F x_{k}+G u_{k}, \mathbf{a}_{k}, \alpha_{k}\right) \mid Z_{k}>
\end{aligned}
$$

上式は, $x_{k}, \mathbf{a}_{k}, \alpha_{k}$ の多項式関数に関する推定值および $u_{k}$ の 統計量から与えられ, したがって, 推定式(38)および予測式 (43)を交互に組み合わせることにより, 対象信号 $x_{k}$ の逐次推 定が可能になる。

\section{4. 音環境評価への適用}

環境騒音に対する音の大きさと騒音レベルの関係を定量 的に見出すことは, 環境アセスメントの観点から重要であ る(5)。たとえば, 地域の音環境評価においては, 測定による 全数調查が不可能な場合, 地域住民による音の大きさ（ラ ウドネス）に対するアンケート調査がしばしば行われてい る。したがって，人閒によるラウドネス評価值のデータに 基づき, 騒音レベルを推定することは大変重要である。一 般に，人間のラウドネスに対する感覚は，７段階（例えば，

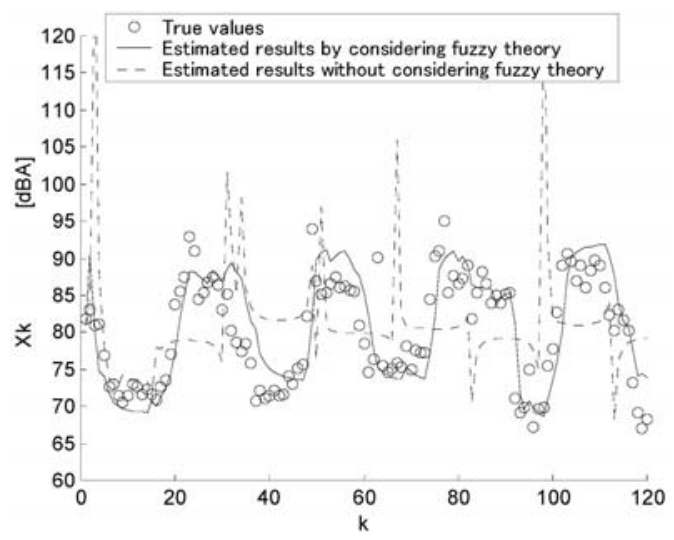

図 3 被験者 $\mathrm{A}$ によるラウドネスの逐次評価に基づく騒音 レベル変動波形の推定結果（データ 2 の場合）

Fig. 3. Estimation results of the fluctuation waveform of the sound level based on the successive judgment on loudness scores by a subject A (for Data 2).

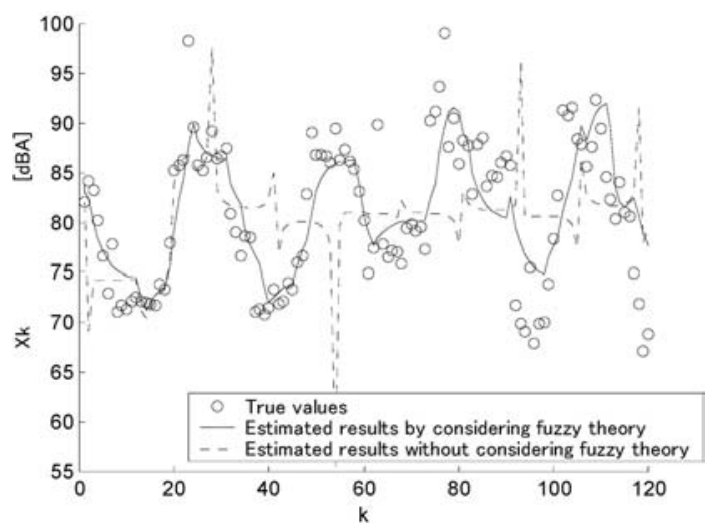

図 4 被験者 $\mathrm{B}$ によるラウドネスの逐次評価に基づく騒音 レベル変動波形の推定結果（データ 2 の場合）

Fig. 4. Estimation results of the fluctuation waveform of the sound level based on the successive judgment on loudness scores by a subject B (for Data 2). 


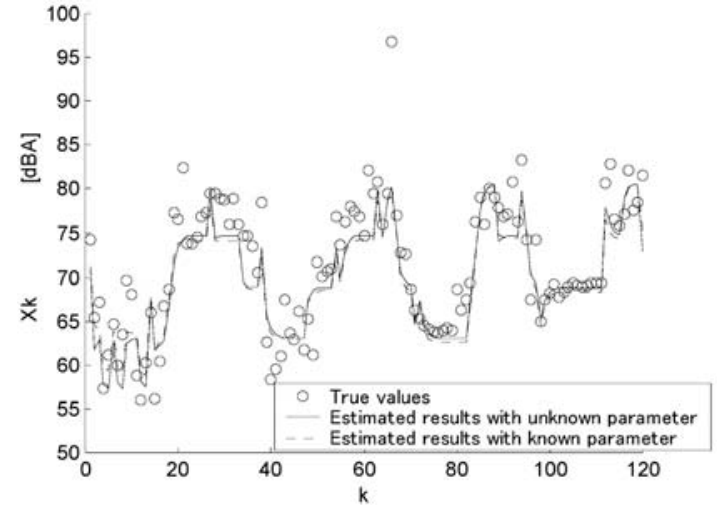

図 5 被験者 $\mathrm{A}$ によるラウドネスの逐次評価に基づく騒音 レベル変動波形に関する推定結果の比較（データ 1 の場合）

Fig. 5. Comparison between two estimated results for the fluctuation waveform of the sound level based on the successive judgment on loudness scores by a subject A (for Data 1).

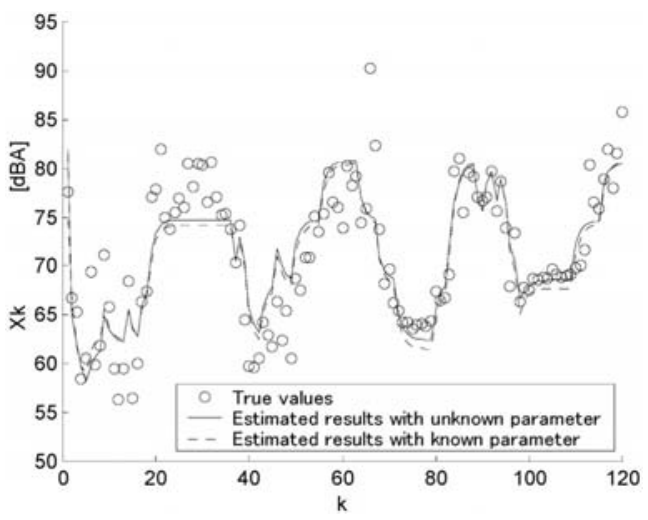

図 6 被験者 $\mathrm{B}$ によるラウドネスの逐次評価に基づく騷音 レベル変動波形に関する推定結果の比較（データ 1 の場合）

Fig. 6. Comparison between two estimated results for the fluctuation waveform of the sound level based on the successive judgment on loudness scores by a subject B (for Data 1).

1. 非常に静か, 2. 静か, 3. 大体静か， 4. 少し騒々しい, 5. 騒々しい，6. かなり騒々しい，7. 非常に騒々しい）で識 別できることが心理音響学で知られている(3)。

実験は，国道 2 号線治いで測定した道路交通騒音をデー タレコーダに録音した後, 実験室でこれを再生し, 正常な 聴覚を持つ 22 歳から 24 歳までの 6 人の被験者 (A, B, C, D, $\mathrm{E}, \mathrm{F}$ とする）が刻々と変化する音を聞いて, その印象を 5 秒ごとに上述の 7 つのカテゴリーで判断した。ここでは, 交通量が比較的に少ないときと多いときの 2 種類のデータ について実験を行った。前者の場合, 騒音レベルの平均值 は $71.4[\mathrm{dBA}]$ で，後者では 80.2[dBA]であった（それぞれ， データ 1 およびデータ 2 とよぶ)。このようにして得られた ラウドネス評価值をファジィ観測值 $z_{k}$ とみなし, 騒音レベ ル $x_{k}$ の変動波形を推定した。

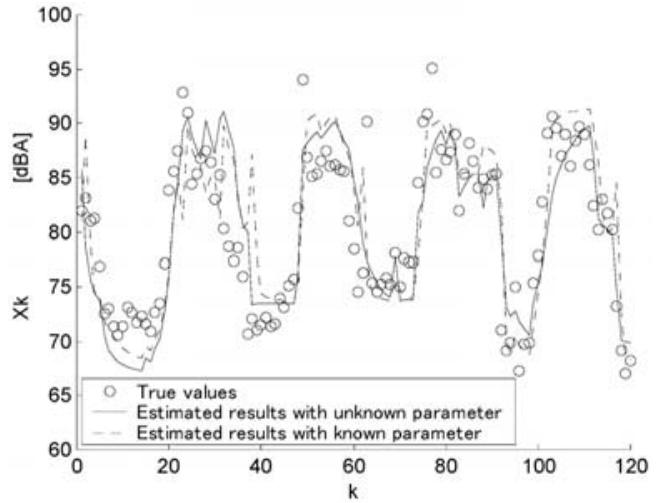

図 7 被験者 $\mathrm{A}$ によるラウドネスの逐次評価に基づく騒音 レベル変動波形に関する推定結果の比較（データ 2 の場合）

Fig. 7. Comparison between two estimated results of the fluctuation waveform for the sound level based on the successive judgment on loudness scores by a subject A (for Data 2).

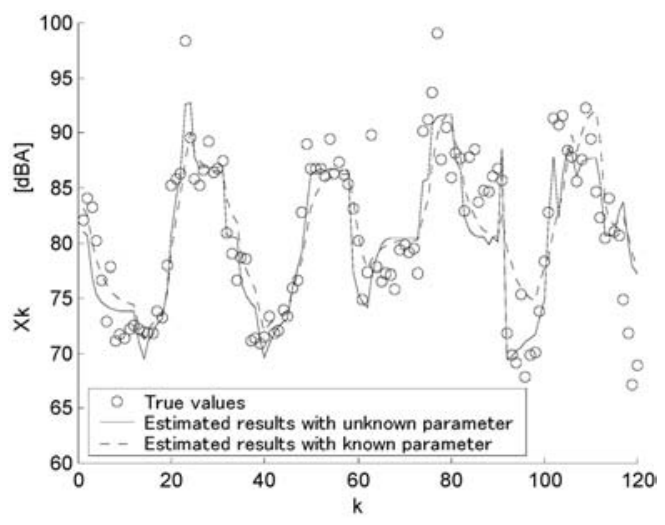

図 8 被験者 $\mathrm{B}$ によるラウドネスの逐次評価に基づく騒音 レベル変動波形に関する推定結果の比較（データ 2 の場合）

Fig. 8. Comparison between two estimated results of the fluctuation waveform for the sound level based on the successive judgment on loudness scores by a subject B (for Data 2).

表 1 データ 1 に対する推定の $\mathrm{rms}$ 誤差 [dBA]

Table 1. Root mean squared error of the estimation for Date 1 in $[\mathrm{dBA}]$.

\begin{tabular}{|l|c|c|c|c|c|c|}
\hline Subject & A & B & C & D & E & F \\
\hline $\begin{array}{l}\text { Proposed } \\
\text { Method } \\
\text { (Sect. 3.1) }\end{array}$ & 3.65 & 3.63 & 4.51 & 4.62 & 4.89 & 4.56 \\
\hline $\begin{array}{l}\text { Proposed } \\
\text { Method } \\
\text { (Sect. 3.2) }\end{array}$ & 3.61 & 3.65 & 4.45 & 4.52 & 5.06 & 4.77 \\
\hline $\begin{array}{l}\text { Compared } \\
\text { Method }\end{array}$ & 7.55 & 4.10 & 15.8 & 5.06 & 5.13 & 5.75 \\
\hline
\end{tabular}


表 2 データ 2 に対する推定の $\mathrm{rms}$ 誤差 [dBA]

Table 2. Root mean squared error of the estimation for Date

2 in [dBA].

\begin{tabular}{|l|c|c|c|c|c|c|}
\hline Subject & A & B & C & D & E & F \\
\hline $\begin{array}{l}\text { Proposed } \\
\text { Method } \\
\text { (Sect. 3.1) }\end{array}$ & 4.59 & 4.26 & 4.82 & 6.80 & 7.49 & 4.65 \\
\hline $\begin{array}{l}\text { Proposed } \\
\text { Method } \\
\text { (Sect. 3.2) }\end{array}$ & 4.18 & 3.66 & 4.61 & 5.88 & 6.22 & 3.92 \\
\hline $\begin{array}{l}\text { Compared } \\
\text { Method }\end{array}$ & 10.7 & 7.79 & 4.96 & 14.6 & 11.6 & 4.64 \\
\hline
\end{tabular}

$\langle 3 \cdot 1\rangle$ 節で提案したファジィ確率に基づく手法を適用し たときの推定結果の一部を図 1 亿示寸（被験者 $\mathrm{A}$ でデー夕 1 の場合)。この図で, 横軸は推定の繰り返し時刻 $k$ を, 縦 軸は騒音レベルを表す。本手法との比較のため, 同図には ファジィ理論を用いず，既発表(2)(6) と同様の推定アルゴリズ ムを適用した場合の推定結果も併せ示す。具体的には, (8) 式においてメンバーシップ関数を考慮せずに導出される状 態推定法を適用してみた。本手法は騒音レベル変動を精度 よく推定しているのに対し，ファジィ理論を考慮しない場 合は推定誤差がかなり大きいことがわかる。被験者 B の評 価データに適用したときの推定結果を図 2 に示す。また, データ 2 に対する推定結果の一部を図 3 および図 4 に示す。 いずれも，本手法はファジィ理論を考慮しない場合に比べ て, 騒音レベルの変動波形をより良く推定していることが わかる。

次に, $\langle 3 \cdot 2\rangle$ 節で提案した推定アルゴリズムを適用した 結果の一部を図 5～図 8 に示寸。これらの図で, “Estimated results with unknown parameter"はメンバーシップ関数のパラ メータも未知として $x_{k}$ と同時に推定する $\langle 3 \cdot 2\rangle$ 節の手法を 適用したときの結果であり, “Estimated results with known parameter”は $\langle 3 \cdot 1\rangle$ 節で提案した手法を適用したときの推定 結果である。さらに，全ての被験者によるラウドネス評価 データに 3 種の推定手法を適用したときの, 推定の平均自 乗誤差を表 1 （データ 1 の場合）および表 2 （データ 2 の場 合）に示す。これらの表において, “Compared Method”は, (8) 式においてメンバーシップ関数を導入せずに, 既発表(2)(6) 同様の推定アルゴリズムを適用したときの推定結果であ る。メンバーシップ関数の導入に基づく本手法による推定 結果は，ファジィ理論を考慮しない場合に比べて，精度の 良い推定が得られていることが数值的に伺われる。さらに, メンバーシプ関数のパラメータをも未知とし，対象騒音と 同時に推定した〈3·2〉節の手法のほうが，全般的により高 精度の推定結果が得られていることがわかる。

\section{5. おわりに}

本研究では，あいまいさの混入したファジィ観測データ に基づき, 構造未知の複雑な音環境システムにおける対象 信号を推定するための一手法を提案した。具体的には，シ ステムの入出力関係を, 既発表の条件付確率分布で捉え,
ファジィ事象の確率およびファジィ事象のモーメントを導 入することにより, 新たな状態推定法を導出した。さらに, 提案した手法を音環境における心理実験に適用して, 実験 的にも検討を行った。

本研究は音環境システムの状態推定に関する従来の標準 的手法とは異なってファジィ理論導入の有効性を示寸解析 路線上にあり, 当然まだ研究の初期段階で, 実験も原理的 確認の段階に留まっている。従って, 今後, この基礎研究 の上に積み上げるべき多くの方法論的改善や実問題への将 来課題が残されている。例えば,

(i) 提案した手法を, システム特性に未知要因やあいまい さを含む多くの音環境や他の実システムへ適用して，その 実際的有効性を多く確認していくこと，

(ii) 複数の対象信号が存在する場合など多変数システム 一理論を拡張すること，

(iii) 暗騒音のような外来雑音が存在する実際的状況下 において適用可能なように理論を発展させること, などが 考えられる。

(平成 18 年 3 月 3 日受付, 平成 18 年 10 月 2 日再受付)

\section{文献}

(1) M. Ohta, A. Ikuta, and N. Takaki : "A New Trial of Regression Analysis with Less Information Loss and Its Application to Sound Insulation Walls - Matching to the Prediction of Response Probability Distribution", J. of the Acoustical Society of Japan, Vol.44, No.11, pp.848-856 (1988-11) (in Japanese)

太田光雄 - 生田 顕・高木尚光 : 情報欠損の少ない回帰分析の一試 みと音環境への適用一分布予測への整合性」, 音響誌, 44, 11 , pp.848-856 (1988-11)

(2) A. Ikuta, M. Ohta, and H. Masuike : "A Countermeasure for an External Noise in the Measurement of Sound Environment and Its Application to the Evaluation for Traffic Noise at Main Line", IEEJ Trans. EIS, Vol.126, No.1, pp.63-71 (2006-1) (in Japanese)

生田 顕・太田光雄・益池寿子 : 「音環境計測における外来雑音対策 と幹線交通騒音評価への適用」, 電学論 C, 126, 1, pp.63-71 (2006-1)

（3）難波精一郎・桑野園子：「音の評価のための心理学的測定法」, コロ ナ社，東京 (1998)

(4) S. Yamaguchi, K. Oimatsu, Y. Kato, and T. Saeki : "Psychological Evaluation of External Noise in the Case of Listening to Audio Signal", IEICE Japan, Vol.J77-A, No.11, pp.1433-1442 (1994-11) (in Japanese) 山口静馬 - 老松建成 - 加藤裕一 - 佐伯徹郎 :「音声聴取時の外来雑音 に対する心理的評価」, 信学論, J77-A, 11, pp.1433-1442 (1994-11)

(5) A. Ikuta, M. Ohta, and M. N. H. Siddique : "Prediction of Probability Distribution for the Psychological Evaluation of Noise in the Environment Based on Fuzzy Theory", International J. of Acoust. and Vib., Vol.10, No.3, pp.107-114 (2005)

(6) M. Ohta and H. Yamada : "New Methodological Trials of Dynamical State Estimation for the Noise and Vibration Environmental System Establishment of General Theory and Its Application to Urban Noise Problems", Acustica, Vol.55, No.4, pp.199-212 (1984)

( 7 ) L. A. Zadeh : "Probability Measures of Fuzzy Events", J. Math. Anal. Appl., Vol.23, pp.199-212 (1968)

(8) M. Ohta and T. Koizumi : "General Statistical Treatment of the Response of a Nonlinear Rectifying Device to a Stationary Random Input", IEEE Trans. Inf. Theory, Vol.IT-14, No.4, pp.595-598 (1968) 


\section{付録 $y_{k}$ に対する推定式の導出}

音環境システムの出力 $y_{k}$ に対する任意 $N$ 次多項式 $h_{N}\left(y_{k}\right)$ の推定式は，次式で定義される。

$$
\hat{h}_{N}\left(y_{k}\right) \equiv<h_{N}\left(y_{k}\right) \mid Z_{k}>
$$

条件付期待值の性質と(2)式を用いることにより，(A1)式は 次のように変形される。

$$
\begin{aligned}
\hat{h}_{N}\left(y_{k}\right) & =<<h_{N}\left(y_{k}\right)\left|x_{k}, Z_{k}>\right| Z_{k}> \\
& =<\int h_{N}\left(y_{k}\right) P\left(y_{k} \mid x_{k}\right) d y_{k} \mid Z_{k}> \\
& =\sum_{s=0}^{N} e_{N s}<\mathbf{A}_{(s), k} \Theta\left(x_{k}\right) \mid Z_{k}>\cdots
\end{aligned}
$$

ただし， $\mathbf{A}_{(s), k}$ および $\Theta\left(x_{k}\right)$ は(28)式で定義され， $e_{N s}$ は次の 直交展開式を満足する係数である。

$$
h_{N}\left(y_{k}\right)=\sum_{i=0}^{N} e_{N i} \theta_{i}^{(2)}\left(y_{k}\right)
$$

(A2)式より， $\hat{h}_{N}\left(y_{k}\right)$ は $x_{k}$ および $\mathbf{a}_{k}$ に関する推定式から得ら れることがわかる。

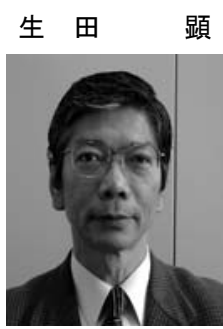

（正員） 1951 年 11 月 5 日生。 76 年 3 月九工 大・工・第 2 部電気卒。 81 年 3 月広島大学大学 院博士課程後期修了。広島大助手, 近畿大助教 授, 県立広島女子大学教授を経て, 現在県立広 島大学教授。信号処理, 確率システムの推定・ 同定，波動環境（騒音・振動・電磁波）の評価 に関する研究に従事。工博。電子情報通信学会, 音響学会，騒音制御工学会などの各会員。

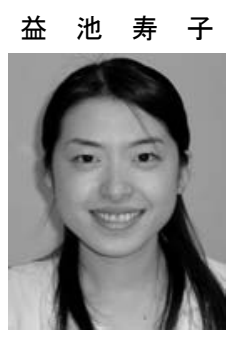

(非会員) 1980 年 8 月 7 日生。 2003 年 3 月県 立広島女子大 - 生活科学 - 生活環境卒業。同年 NTT データ中国入社。ソリューションシステ 厶部勤務。現在, 県立広島大学大学院修士課程 経営情報学専攻在学中。信号情報処理およびデ 一夕解析, 情報通信, 救急医療システムの構築 に関寸る研究開発に従事。

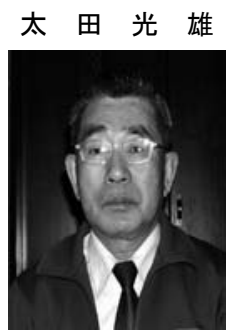

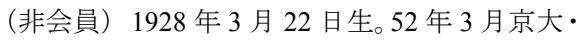
理 - 物理卒業。神戸大 $\cdot$ 工 助教授, 福井大 工・教授，広島大 $\cdot 工 \cdot$ 教授, 近畿大 $\cdot$ 工・教 授を経て，現在広島大・名誉教授。制御・信号 処理, 波動環境（騒音・振動・電磁波）の評価, 通信・情報など, 特に非ガウス・非定常・非線 形の研究に従事。6 6 年日本音響学会佐藤論文 賞, 96 年計測自動制御学会フェロー称号, 98 Int. Inst. Acous. \& Vib. フェロー称号受賞。日本騒音制御工学会認定技 師。環境庁，IMC 及び日本音響学会より功績賞受賞。 